\title{
O emergir de um cânone: Roquette-Pinto e o retrato da nação
}

The emergence of a canon: Roquette-Pinto and the portrait of the nation

\author{
Gerson Pietta ${ }^{i}$ \\ ' Doutorando, Programa de Pós-graduação em História/Universidade Federal do Paraná. \\ Curitiba - PR - Brasil \\ orcid.org/0000-0002-7250-2136 \\ gersonpietta@gmail.com
}

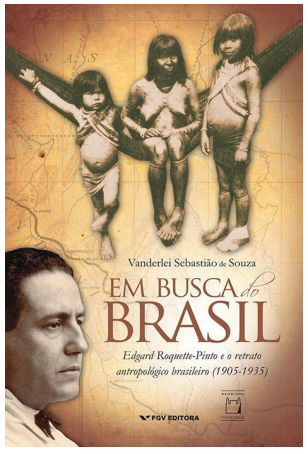

SOUZA, Vanderlei Sebastião de. Em busca do Brasil: Edgar RoquettePinto e o retrato antropológico brasileiro (1905-1935). Rio de Janeiro: FGV Editora; Editora Fiocruz. 2017. 480p.

O livro Em busca do Brasil: Edgard Roquette-Pinto e o retrato antropológico brasileiro (1905-1935), de Vanderlei Sebastião de Souza (2017), é resultado de sua tese de doutorado, premiada em 2013, pela Associação Nacional de História (Anpuh), como a melhor tese na área. O livro discute a trajetória de Roquette-Pinto como antropólogo e intérprete do Brasil, ressaltando o papel de seus estudos antropológicos na defesa de uma nação mestiça, historicamente representada como degenerada e inferior. Um ponto pertinente de Souza é destacar essa ruptura interpretativa a partir da análise dos diálogos e embates de Roquette-Pinto com antropólogos, intelectuais, autoridades públicas, eugenistas e historiadores nacionais e internacionais acerca das teorias raciais e da formação das populações mestiças. Além disso, a partir da análise da circulação internacional de ideias e teorias científicas, tendo acesso a relatórios de pesquisas e esboços de textos, o historiador visualizou as ações criativas e inventivas de RoquettePinto em suas apropriações da antropologia física, que gozava de prestígio e era ferramenta central para a produção de conhecimento e representações da realidade brasileira.

A obra de Souza se diferencia por desconstruir uma linha interpretativa majoritária dos anos 1990, que visualizava a defesa da nação de Roquette-Pinto pela influência cultural de Franz Boas (Ribas, 1990; Stepan, 1995; Lesser, 1995; Barbosa, 1996; Keuller, 2008). O acesso às fontes de cunho estritamente privado - correspondências e anotações críticas de leituras, que, cabe ressaltar, são advindas de árdua busca documental por parte do autor denotaram que Roquette-Pinto não concordava com a visão defendida por Boas de que o ambiente influía sobre a raça, pois o meio não alteraria a estrutura do germe hereditário. Souza desmitifica esse caso e revela que Roquette-Pinto se vinculava ao mendelismo e aos geneticistas alemães e norte-americanos, que davam base metodológica à sua pesquisa ao 
mesmo tempo que eram criticados em aspectos que não apresentavam interesse para a nação brasileira.

Em busca do Brasil analisa, no primeiro capítulo, o lugar social, institucional e intelectual em que Roquette-Pinto esteve inserido nos primeiros anos de sua formação. $\mathrm{O}$ autor percorre a trajetória do antropólogo desde sua formação humanista e positivista, sua formação médica e suas redes de sociabilidades na Faculdade de Medicina do Rio de Janeiro, bem como sua atuação no Museu Nacional e os estudos sobre raças e populações desenvolvidos na instituição. Já no segundo capítulo, "Viagem ao sertão do Brasil", Souza evidencia como ocorreram mudanças intelectuais e psicológicas importantes na formação do antropólogo Roquette-Pinto. Desde a representação negativa do sertanejo a partir da leitura social darwinista de Euclides da Cunha até sua viagem ao interior do país junto à Comissão Rondon, a convivência com Capistrano de Abreu e o contato com as populações indígenas e sertanejas, experiências que lhe possibilitaram reinterpretar a identidade nacional em termos positivos. Assim, o sertanejo passa a ser visto pelo antropólogo como mediador da civilização, distanciando-se das leituras deterministas e aproximando-se da etnologia alemã, baseada no evolucionismo positivista. Essa guinada, evoca Souza, possibilitou a Roquette-Pinto constatar os problemas sociológicos, políticos e de saúde pública do país, negando a existência de problemas raciais ou de hibridismo humano.

No terceiro capítulo, intitulado "O retrato antropológico do Brasil", o autor reflete como a antropologia física foi utilizada por Roquette-Pinto como ferramenta política para produzir um amplo retrato da nação. Desde o final do século XIX, o Brasil era visto como um laboratório de raças, que criou historicamente tipos humanos intermediários, que deveriam ser medidos e classificados. ${ }^{1}$ Souza enumera com êxito as metodologias elencadas por Roquete-Pinto, da antropologia física à biometria e aos estudos de natureza psicofisiológica, com autoridades internacionais como Felix von Luschan, Rudolf Martin, Eugen Fischer, Francis Galton, Karl Pearson, Charles Davenport, Franz Boas e Stanley Porteus. A lei galtoniana da "frequência estatística" foi utilizada por Roquette-Pinto para produzir quatro padrões tipológicos/antropológicos de classificação racial: brancos ou leocodermos, negros ou melanodermos, caboclos ou xantodermos e mestiços ou faiodermos. Souza aponta que apesar de Roquette-Pinto não constatar aspectos de degeneração, deixa perceber a existência de pontos paradoxais. O primeiro era que os cruzamentos tendiam à dominância de caracteres da raça branca, e o segundo, que haveria desigualdade no caráter e temperamento psicológico dos tipos raciais, quando se relacionavam comportamentos a características raciais. Os pontos paradoxais poderiam ser visualizados por Souza como estratégias escolhidas em negociações por conveniências já socialmente aceitas, no entanto, teoricamente, as trajetórias intelectuais não precisam significar uma linha una e coerente (Bourdieu, 1996).

No quarto capítulo, intitulado "Debates sobre a miscigenação racial", Souza revela como Roquette-Pinto articulou seletivamente as teorias científicas a fim de contestar as teses que condenavam a miscigenação racial. Comprovou com dados antropológicos, baseados no mendelismo, que a miscigenação não formava tipos instáveis, inferiores ou degenerados. Ao mesmo tempo, recusou a tese da infertilidade da população, elegendo as questões sociais ante as biológicas, associando-se ao movimento sanitarista e educacional. No entanto, Souza 
trabalha com outro paradoxo do antropólogo: a questão do branqueamento da população. Ou seja, ao mesmo tempo que contrariava a degeneração a partir da miscigenação, acreditava que a média da população nacional seria predominantemente europeia, fosse pelo fim da escravidão e pela imigração europeia, fosse pela tendência branca a dominar as características na miscigenação. Nesse quesito, alinhou-se com outros pensadores e cientistas, como João Batista de Lacerda e Silvio Romero. Contudo, conforme afirmava a tradição antropológica brasileira, há que se destacar que o branqueamento era visualizado sob um panorama positivo, pressupondo uma miscigenação saudável.

No quinto capítulo, "Eugenia, população e imigração", Souza infere como Roquette-Pinto articulou o conceito de eugenia. Crendo na possibilidade de aperfeiçoamento humano, lutou contra práticas radicais no Brasil e contra a ideia de que miscigenação significava degeneração, aliando eugenia e formação nacional. Assim como Francis Galton, era favorável a um programa eugênico que incentivasse a reprodução de casais bem constituídos, e ainda não desvinculava a eugenia da hereditariedade e da biometria, pois a primeira negava a influência do meio e estudava as leis e os processos genéticos, e a segunda evidenciava a variação e a frequência dos caracteres. Souza enumera os argumentos de Roquette-Pinto relativos às diferenças entre a eugenia mendelista, vista como biologia da herança, e a eugenia neolamarckista, vista como higiene. Por outro lado, Souza relata que o antropólogo foi decisivo nas discussões acerca da imigração, quando se colocou contrário à substituição dos brasileiros por novos imigrantes europeus ou quando, em 1934, após a aprovação das leis de esterilização alemã, o jornal O Globo lançou um inquérito sobre a temática, no qual Renato Kehl, Pacheco da Silva, Leonídio Ribeiro e Oscar Fontanelle se colocavam favoráveis à sua aplicação, em oposição a Leitão da Cunha e ao próprio Roquette-Pinto, críticos das posições eugênicas mais radicais.

O livro Em busca do Brasil se coloca como um marco na historiografia acerca dos intérpretes do Brasil, por sua análise inovadora da trajetória intelectual de Roquette-Pinto e sua ruptura interpretativa a partir da antropologia física e pela instigante narrativa sobre os diálogos e embates intelectuais nos quais o antropólogo brasileiro esteve envolvido. Por findar o recorte temporal em 1935, a obra de Souza abre uma gama de possibilidades de pesquisas na história das ciências, já que Roquette-Pinto, por sua trajetória, ocupa uma posição de cânon diante de gerações de cientistas que se debruçam sobre os estudos das populações em perspectiva antirracista, sejam eles geneticistas, demógrafos, médicos ou cientistas sociais.

\section{NOTA}

${ }^{1}$ A classificação racial ocorria pela coleta de dados como cor de pele, tipo de cabelo, estatura, perímetro do tórax, impressões digitais, índices facial, cefálico e nasal, que, a partir do eixo racial triplo, branco, negro e indígena, retrataria tipos intermediários (Souza, 2017, p.215).

\section{REFERÊNCIAS}

BARBOSA, Ana Maria de Souza.

O pássaro dos rios nos afluentes do saber: Roquette-

Pinto e a construção da universalidade. Tese
(Doutorado em Ciências Sociais) - Pontifícia Universidade Católica de São Paulo, São Paulo. 1996. 
BOURDIEU, Pierre.

A ilusão biográfica. In: Bourdieu, Pierre. Razões práticas: sobre a teoria da ação. Trad. Mariza Corrêa. Campinas: Papirus. p.74-82. 1996.

KEULLER, Adriana.

Estudos físicos de antropologia no Museu Nacional do Rio de Janeiro: cientistas, objetos, idéias e instrumentos (1876-1939). Tese (Doutorado em História) - Universidade de São Paulo, São Paulo. 2008.

LESSER, Jeffrey.

Welcoming the undesirables: Brazil and the Jewish question. Berkeley: University of California Press. 1995.
RIBAS, João Baptista Cintra.

O Brasil é dos brasilianos: medicina, antropologia e educação na figura de Roquette-Pinto.

Dissertação (Mestrado em Antropologia Social) Universidade Estadual de Campinas, Campinas. 1990.

SOUZA, Vanderlei Sebastião de.

Em busca do Brasil: Edgar Roquette-Pinto e o retrato antropológico brasileiro (1905-1935). Rio de Janeiro: FGV Editora; Editora Fiocruz. 2017.

STEPAN, Nancy.

A hora da eugenia: raça, gênero e nação na América Latina. Rio de Janeiro: Editora Fiocruz. 2005. 